\title{
Competência dos enfermeiros na atuação como educador em saúde*
}

\author{
Competences of nurses acting as educators of health \\ Capacidad de los enfermeros en su desempeño como educadores en salud
}

\author{
Vânia Marli Schubert Backes', Mônica Motta Lino', Marta Lenise do Prado", \\ Kenia Schimidt Reibnitz', Bruna Pedroso Canaver ${ }^{1}$ \\ 'Universidade Federal de Santa Catarina. Departamento de Enfermagem. \\ Pós-Graduação em Enfermagem. Grupo de Pesquisa EDEN/UFSC. Florianópolis, SC
}

Submissão: 18/02/2008

Aprovação: 24/10/2008

\section{RESUMO}

Pesquisa avaliativa, com análise Qualitativa, Que teve como objetivo avaliar o impacto do curso de Especialização em Projetos Assistenciais em Enfermagem - ESPENSUL gerado no processo de trabalho dos Enfermeiros egressos, no Que tange a competência de atuar como educador em saúde junto à equipe, cliente e familiares no desempenho de suas funções. Este Curso foi desenvolvido em cinco Instituições Federais: UFSC, UFPR, UFSM, UFPel e FURG. A amostra estratificada proposital selecionada contemplou 10\% do total de egressos, compreendendo 32 sujeitos. O referencial da educação em saúde como um processo dialógico, inclusivo e problematizador estimulou nos Enfermeiros mudanças no processo educacional da sua prática e envolveu não somente a intencionalidade do Curso e de seus professores, mas sim, um comprometimento de todos neste processo de mudança.

Descritores: Enfermagem; Educação contínua/permanente; Estudos de avaliação; Educação à distância; Educação em saúde.

ABSTRACT
This is an evaluative study, with Qualitative analysis, which has as an objective in evaluate the impact of the specialization in Assistant Projects of Nursing - ESPENSUL created in the working process of specialist nurses, in what relates to the competence of acting as an educator of health together as a team, clients and families in carrying out their functions. This course was develop in five Federal Institutions: UFSC, UFPR, UFSM, UFPL e FURG. An example of a propose selection shows that 10\% of the total specialist, understand 32 people. The reference in health education as a process of dialogue, inclusive and problematical, stimulant the nurses of the changes in the educational process of their daily practice and, henceforth not only intentionally of the course and its professors, but, the compromise of all in this process of change.

Descriptors: Nursing; Permanent education; Evaluation studies; Distance education; Health Education.

\section{RESUMEN}

El presente estudio trata de una investigación realizada a partir del análisis cualitativo, la cual tuvo como objetivo evaluar el impacto generado por el Curso de Especialización en Proyectos Asistenciales en Enfermería - ESPENSUL, en el proceso de trabajo de los enfermeros egresados, en lo que se refiere a su capacidad para desempeñarse en el desarrollo de sus funciones como educadores en salud junto al equipo de trabajo y familiares. El Curso fue realizado en cinco Instituciones Federales: UFSC, UFPR, UFSM, UFPel y FURG. La muestra estratificada de propósito, consideró el 10 por ciento del total de los egresados, siendo formada por 32 sujetos. El referencial de la educación en salud como proceso dialógico, inclusivo y problemático, produjo cambios en los enfermeros en el proceso educacional de su práctica diaria, incluyendo no sólo la intencionalidad del Curso y de sus profesores, sino también, el compromiso de todos los participantes en ese proceso de cambio. Descriptores: Enfermería; Educación permanente; Estudios de evaluación; Educación a distancia; Educación en salud. 


\section{INTRODUÇÃO}

O Projeto ESPENSUL - Especialização em Enfermagem da Região Sul, emergiu da necessidade de Qualificação da força de trabalho da Enfermagem na região sul do País, tendo em vista a especialização de Enfermeiros em seus locais de trabalho, proporcionando ao Enfermeiro desenvolver seus estudos em seu contexto, inserido nos serviços de saúde.

Contou com o envolvimento e participação de cinco Instituições Federais de Ensino Superior da Região Sul do Brasil, a saber: Universidade Federal de Santa Catarina (UFSC), Universidade Federal do Paraná (UFPR), Universidade Federal de Santa Maria (UFSM), Universidade Federal de Pelotas (UFPel) e Universidade de Rio Grande (FURG).

Construído coletivamente, este Curso foi o motivo e motivador das ações das pessoas e instituições envolvidas. Foi o horizonte vislumbrado ao Qual esforços coletivos se dirigiram e do Qual se buscou não desviar, adotando como bússula o processo de avaliação(I).

O ESPENSUL integrou a modalidade Educação à Distância e metodologia problematizadora, como um caminho Que possibilitasse maior cobertura da população de Enfermeiros na sua realidade de trabalho, ao lado de um compromisso com a Qualidade dessa formação em suas características de cidadania, de crítica e de resolutividade das situações de saúde. Esta característica nãopresencial estimula o estudo individual e torna o aluno protagonista do próprio aprendizado, tecendo condições para tal, com auxílio de recursos e enfoques metodológicos apropriados. Permite, ainda, Que ao profissional-aluno, acionar a equipe de apoio a Qualeuer momento, para esclarecimentos ou reforços necessários.

A proposta desta modalidade de ensino foi um desafio e um compromisso ímpar. "Desafio do novo, do diferente; compromisso de integrar educação e trabalho, ensino e serviço, tomando como base, a vivência diária do profissional e estimulando a consciência crítica e a reconstrução de seu Quotidiano, seja através do processo reflexivo a ser desencadeado pela proposta do Curso, seja pelo envolvimento da equipe de trabalho como parceiros na busca de resultados operacionais concretos"(2).

Compreendeu-se Que, Quando se propiciam espaços para Que os alunos se apropriem de maneira significativa, crítica e criativa do conhecimento acumulado, bem como exercitam uma práxis transformadora, há a possibilidade deste conhecimento ser emancipador, colaborando com a construção da cidadania e com o envolvimento na transformação da realidade.

Este artigo tem o objetivo de avaliar o impacto gerado no processo de trabalho dos Enfermeiros egressos do curso de Especialização em Projetos Assistenciais em Enfermagem, no Que tange a competência em atuar como educador em saúde junto à equipe, cliente e familiares no desempenho de suas funções.

Trata-se de competência importante e inerente ao trabalho do Enfermeiro, Que deve ser continuamente desenvolvida e avaliada, visto que "a educação em saúde como processo político pedagógico requer o desenvolvimento de um pensar crítico e reflexivo, permitindo desvelar a realidade e propor ações transformadoras Que levem o indivíduo a sua autonomia e emancipação enQuanto sujeito histórico e social capaz de propor e opinar nas decisões de saúde para o cuidar de si, de sua família e da coletividade"(3).

\section{METODOLOGIA}

Este estudo identifica-se como uma pesquisa de abordagem Qualitativa e envolve a obtenção de dados descritivos, obtidos no contato com a situação estudada, enfatiza mais o processo do que o produto e se preocupa em retratar a perspectiva dos participantes ${ }^{(4)}$. Ainda, esta abordagem de estudo "baseia-se na premissa de que os conhecimentos sobre os indivíduos só são possíveis com a descrição da experiência humana, tal como ela é vivida e tal como ela é definida por seus próprios atores"(5).

Entende-se que "a abordagem Qualitativa da avaliação de impacto é aQuela Que não se baseia em evidências fornecidas pelo elemento contrafatual para se chegar a inferências causais" ${ }^{(6)}$. Neste sentido, é necessário buscar estabelecer relação causal entre as ações do curso e os comportamentos, atitudes ou ações das pessoas Que o desenvolveram. A abordagem de avaliação de impacto adotada foi a avaliação ex-post facto, Que visa reconstituir os elementos necessários a uma estimativa do impacto a partir de documentos e de entrevistas com os atores do processo ${ }^{(7)}$.

Este artigo é uma parcela de um grande projeto de pesquisa intitulado "Avaliação de Impacto da Práxis Cotidiana dos Enfermeiros Especialistas em Projetos Assistenciais", Que visa avaliar o impacto do Curso ESPENSUL nas Enfermeiras Especialistas. O Curso foi composto de cinco momentos (módulos) de aprendizagem, Que problematizavam a realidade dos Enfermeiros (Momento Zero O nascente ESPENSUL; Momento I - A Enfermagem e as Políticas de Saúde no Brasil; Momento 2 - O Processo de Trabalho na Enfermagem e na Saúde; Momento 3 - Conceitos e Visões Teóricas e Momento 4 - Desenvolvimento Coletivo do Projeto Assistencial. Reafirma-se o delineamento escolhido, sendo avaliado aqui, apenas uma das competências do Curso: atuar como educador em saúde junto à equipe, cliente e familiares, no desempenho de suas funções. Para tanto, foram realizadas entrevistas estruturadas com base nesta competência e análise dos módulos de aprendizagem requeridos pelo Curso.

A amostra estratificada proposital selecionada neste estudo contemplou 10\% do total de Egressos do Curso, de cada turma das instituições participantes, compreendendo 32 sujeitos.

Para sua realização, este estudo foi aprovado pelo Comitê de Ética em Pesquisa com Seres Humanos - CEP/UFSC com o parecer $\mathrm{n}^{\circ}$ 047/05, em acordo com a resolução CNS 196/96. Assegurouse a todos os envolvidos o anonimato e a liberdade de participação no estudo, bem como desistência deste a QualQuer momento. Para preservar o anonimato, as cinco instituições participantes estão representadas pelos cinco continentes do planeta, bem como os sujeitos, representados por países e mar correspondentes.

\section{RESULTADOS E DISCUSSÃO}

O Curso ESPENSUL propiciou a conquista de várias competências viáveis e execüíveis no ambiente de trabalho dos Enfermeiros especialistas, com o intuito de afastar-se do modelo tradicional de especialidades clínicas na área da saúde. Destacouse uma nova visão na Qual se contextualiza a realidade vivida e a articulada com estratégias críticas, criativas e coletivas, proporcionando uma efetiva contribuição e alteração da prática habitual de fazer e produzir saúde. O Curso certificou os 
Enfermeiros como Especialistas em Projetos Assistenciais em Enfermagem, afastando-se da certificação por especialidades, permitindo a construção de projetos coletivos voltados à resolução de problemas nos serviços de saúde.

Neste sentido, em acordo com a análise dos dados contidos nos módulos de aprendizagem e dos depoimentos dos sujeitos diante da competência em atuar como educador em saúde junto à equipe, cliente e familiares no desempenho de suas funções administrativas, assistenciais e educativas, emergiram cinco categorias:

- Educação dirigida ao usuário e à família na assistência;

- Educação para e com a equipe de Enfermagem;

- Educação como formação básica e continuada;

- Educação na perspectiva de aliança de saberes;

- Contribuição do ESPENSUL na aQuisição da competência.

A categoria Educação dirigida ao usuário e à família na assistência enfatizou diversos aspectos dos sujeitos relacionados ao processo educativo durante a prática assistencial, sendo percebido Que, para alguns, o entendimento de educação enQuanto repasse de informações e orientações ainda persiste. "A gente todo dia orienta paciente, familiar, pessoas Que muitas vezes te procuram até pra pedir opinião, para pedir uma orientação." (Angola) "Tem paciente que, às vezes, tem Que orientar tudo. Sempre que chega a primeira vez, é orientação. Então é sempre educação com as famílias." (Grécia)

Este "repasse de informações" enfatiza Que os Enfermeiros, como educadores, têm colaborado mais no fortalecimento da educação bancária Que da educação transformadora. Esta visão também é observada na prática de outros profissionais da saúde, nas relações Que estabelecem com os usuários e familiares, desconsiderando a multidimensionalidade deste processo. Talvez isto ocorra devido ao modelo tradicional dos cursos de graduação, cuja transferência do conhecimento se faz de modo fragmentado, com ênfase no racionalismo técnico, centrada no professor, com modelos de ensino/avaliação Que privilegiam a memorização e reprodução de conhecimento e alunos tendendo a uma atitude passiva de absorção, portanto, acríticos ${ }^{(8)}$.

A educação não é sinônimo de transferência de conhecimento pela simples razão de Que não existe um saber feito e acabado, suscetível de ser captado e compreendido pelo educador e, em seguida, depositado nos educandos. Freire ${ }^{(9)}$ elucida Que a educação a partir da transmissão de informações consiste numa educação bancária, pois "Quanto mais se exercitem os educandos no arQuivamento dos depósitos Que lhes são feitos, tanto menos desenvolverão em si a consciência crítica de Que resultaria a sua inserção no mundo, como transformadores dele. Como sujeitos".

Outros sujeitos explicitam um processo de repasse de informações aos usuários da saúde Que não contempla estímulo crítico-criativo da realidade em Que se encontram, centrando-se em rotinas, em "fazeres" antigos, arraigados em práticas acríticas, fundamentadas no "tem que ser" em vez do "por Que é assim?". "Quando a gente faz de um jeito Qualquer pessoa Que a gente vá orientar acaba fazendo mais ou menos da mesma maneira." (Brasil)

Os sujeitos do processo educativo posicionam-se passivamente na medida em Que se adaptam frente à realidade. A visão bancária de ensino dificulta, segundo Freire ${ }^{(9)}$, um "pensar autêntico". Indica
Que educar não significa adestrar, mas desenvolver capacidade de aprender como um sujeito crítico, epistemologicamente curioso, Que constrói o conhecimento ou participa de sua construção. Exige apreensão da realidade, não para adaptação, mas para a transformação, para a intervenção e recriação desta realidade ${ }^{(10)}$.

A práxis, Que implica a ação e reflexão dos homens sobre o mundo para transformá-lo. É necessário, Que, para a ação, não se usem as mesmas armas da dominação adotadas pela concepção "bancária", mas que se tenha consciência de Que o educando não é um ser "vazio", pois traz consigo vivências Que devem ser respeitadas ${ }^{(1)}$.

Contudo, outros sujeitos manifestaram um entendimento de educação em saúde de uma forma mais ampliada, Que contemplou autocuidado, autonomia, Qualidade de vida, fundamentada a partir do diálogo e problematização, conforme indica Alemanha.

O tempo inteiro você ta educando você ta ensinando, você ta mostrando e ta aprendendo também. Na medida que você ta com eles (equipe, pacientes, familiares), ta explicado alguma coisa, você também ta aprendendo. Acho que assim educação, educadora, é o tempo inteiro. (Alemanha)

$\mathrm{Na}$ educação problematizadora, na concepção de Freire ${ }^{(12)} \mathrm{o}$ educador já não é o Que apenas educa, mas o Que, enquanto educa, é educado, em diálogo com o educando Que, ao ser educado, também educa. Desta forma, a "prática pedagógica centrada no diálogo, fundada na relação dialógico-dialética, entende educador e educando numa educação problematizadora (...), em Que ambos tornam-se sujeitos do processo ensinoaprendizagem"(10).

O processo educativo em saúde procura envolver os usuários e familiares na construção e significação do autocuidado, valorizando por meio do diálogo, os conhecimentos Que os sujeitos envolvidos detêm a respeito do tema, objeto de estudo e compreensão da realidade vivenciada ${ }^{(13)}$. Isto promove responsabilidade e participação ativa na implementação de cuidados e melhorias da saúde.

Eu procuro dar responsabilidade não só pro paciente, como pro familiar. Eu acho assim, ali dentro da instituição é uma possibilidade, é uma forma que eu tenho de mostrar como ele pode se cuidar, o que ele deve fazer pra ter uma vida melhor. Como a família pode participar. (Somália)

Com clientes e familiares, na clínica onde eu atuo é de fundamental importância essa educação, tanto preventiva, onde a gente pode atuar preventivamente em pessoas: nos diabéticos, nos hipertensos e orientações também de fumo, álcool, a gente faz essas orientações. E também pra pacientes em pósoperatório, onde modificam sua vida, com a cirurgia que muitas vezes alteram a imagem. Então a gente tem Que trabalhar bastante com o cliente e familiares nesse sentido. (Índia)

Esta responsabilidade pode ser entendida como componente importante da promoção de saúde, preocupação Que parece estar ligada ao princípio de empoderamento, entendido como processo de capacitação dos indivíduos e comunidades para assumirem maior 
controle sobre os fatores pessoais, sócio-econômicos e ambientais Que afetam a saúde ${ }^{(14)}$.

Índia indica a educação em saúde com enfoque preventivo e como promotor da saúde, sendo que "a educação para a saúde é, pois, uma estratégia da promoção da saúde. No entanto, ambos os conceitos [educação e promoção] têm sido utilizados freqüentemente, de forma intercambiável. Contudo, é importante diferenciar entre a promoção da saúde como um conceito amplo, Que inclui distintas estratégias de atuação, e a educação para a saúde como um instrumento ou uma estratégia concreta para a promoção da saúde ${ }^{(15) "}$.

Ainda no contexto da promoção de saúde, Nigéria ressalta a importância de retornar à Atenção Básica para efetuar um processo de educação em saúde e que o "retorno" do processo educativo, ou seja, a ação, incorporação e intervenção dos sujeitos para a transformação da realidade em Que vivem, pode ser lenta e gradual, pois assim ela será assimilada e se tornará uma constante no processo de viver.

Temos que voltar um pouco pra Atenção Primária, levar um pouco essa educação pra Atenção Primária e a partir daí a gente vai conseguir algum resultado e essa é a nossa principal função de tantas outras na saúde. Às vezes o processo todo de educação é tão demorado, é tão gradativo, aos poucos. Até se demora um pouco pra ter retorno, eu acho que é constante. (Nigéria)

Outro enfoque de educação em saúde leva em conta a realidade dos indivíduos para, a partir disso, realizar um processo educativo ampliado, transformador, dentro do contexto social dos sujeitos envolvidos.

Acho que é bem forte essa Questão tanto de Enfermeira como educadora. Até mesmo essa Questão da importância da atividade física, a Questão da espiritualidade, da importância de se acreditar em alguma coisa. Com os pacientes, além das orientações e dos treinamentos que a gente dá, a Questão de cuidados com a pessoa, no fazer os exames, o preventivo da mulher. Não só específico da doença. Ver o ser como um todo. É Questão de se organizar pra fazer alguma atividade. (Tailândia)

A educação transformadora é avessa ao modelo convencionalmente desenvolvido: com uma orientação fortemente biologicista e centrado na doença. Essa ação educativa se pauta no estímulo ao exercício crítico-reflexivo de reconstrução do seu próprio processo, se fundamenta na realidade e constrói conhecimento, gerando transformações Que são necessárias nas situações vivenciadas no cotidiano ${ }^{(10)}$.

Na categoria Educação para e com a equipe de Enfermagem, a maioria dos sujeitos enfoca educação em saúde num aspecto voltado à treinamentos, atualização e capacitação. Desta forma, os sujeitos da pesQuisa, versaram sobre a educação em saúde junto à equipe, focando na importância de manter o grupo de trabalho atualizado, como podemos observar nos depoimentos de Argélia e Índia.

“Como Enfermeira, priorizo a educação em saúde com a equipe, a gente sempre procura discutir e atualizar, sempre manter a equipe atualizada. Discutir fatos." (Índia)

Tudo que eu vou pegando, vou levando. Acho que a gente tem Que socializar aquele conhecimento; o grupo todo tem que ta instrumentalizado. Então eu levo muito isso e cobro isso. (Argélia)

Os depoimentos demonstram a preocupação em corresponder com os avanços tecnológicos nos serviços de saúde e com isso a necessidade de educação no trabalho ligada às demandas de atualização profissional. Não se nega a importância do conhecimento técnico-científico, contudo ele não abarca as demais necessidades de ordem pessoal, institucional e mesmo profissionais ligadas a uma maior inovação na assistência prestada e maior satisfação no trabalho ${ }^{(16)}$.

lá Mar da Tasmânia explicita a educação no trabalho, não apenas no controle do certo/errado, mas levando em conta o significado para a eQuipe da ação correta.

Na equipe que eu estou hoje, a gente vê supervisão como uma coisa do processo de aprender, não só de controle. Tu tens Que ta educando na mesma hora que tu faz supervisão, Que tu vê Que tem uma coisa errada da técnica ou do atendimento, acho Que tem Que estar ensinando a forma correta de trabalho. Não existe mais só controle. A gente é educadora a todo momento. (Mar da Tasmânia)

Alguns sujeitos, como demonstrado logo abaixo na fala de França, também passaram a atuar na perspectiva de romper com o modelo vigente, voltado à doença. Neste sentido, "a Enfermeira não precisa, apenas, saber fazer, mas saber por Que faz. Precisa resgatar o caráter reflexivo e voluntário das práticas dos trabalhadores em saúde, através das Quais não somente se fixam em regras de condutas, mas procuram transformar-se, modificarse, reconhecendo certas insuficiências das suas próprias práticas e os limites à expressão criativa imposta por esta forma de trabalho"(10).

Eu cheguei aqui e constatei que todo mundo é centrado na assistência dentro do modelo médico. Acho que as pessoas da equipe não têm essa visão, Que elas têm um papel educativo. Então isso é um processo Que gradativamente estou resgatando, buscando fazer um trabalho mais educativo. (França)

O trabalho educativo reforça a relação entre educação em saúde e promoção de saúde, enQuanto conceitos fortemente associados. Ainda, "a análise crítica levada a efeito conclui Que o ideário da promoção à saúde pode contribuir para a ruptura entre as velhas e novas práticas em saúde, fornecer elementos para transformação do status Quo sanitário e para a produção de sujeitos autônomos e socialmente solidários ${ }^{(17) "}$.

Inserida em um modelo hegemônico na saúde centrado na doença, a prática da Enfermagem ainda é conservadora. "A prática pedagógica não é neutra, seja uma prática pedagógica no ensino formal, num projeto de educação contínua, seja mesmo numa proposta de educação em saúde. As opções pedagógicas adotadas 
refletem as ideologias do contexto em Que se inserem, tendo por base uma concepção de como se Quer Que as pessoas aprendam alguma coisa e, a partir daí, sejam capazes de transformar a realidade, se assim o desejar" (10).

É importante reforçar a promoção da saúde no processo educativo em saúde, para a criação de um novo olhar dos indivíduos com relação ao mundo e no mundo, mesmo Quando a realidade indica Que "o ritmo de vida ditatorial imposto pela sociedade, aparentemente impossível de contrariar, torna utópicas as diretrizes proclamadas pelos conceitos de promoção da saúde, educação para a saúde e prevenção da doença"(15).

"Como educadora, solicito para o meu funcionário que ele se cuide também, para que tenha um trabalho mais tranqüilo." (Somália)

Com a equipe tem treinamentos. Mais essa Questão da Qualidade de vida. De fazer alguma atividade, exercício. Tem um projeto, Que eu participo que tão fazendo aqui no hospital. (Tailândia)

A educação em saúde pode ser "compreendida enquanto Qualidade de vida e não apenas ausência de doença, determinando Que os problemas de saúde sejam enfrentados valendo-se de ações intersetoriais, visto Que extrapolam a responsabilidade exclusiva do setor saúde"(18). Neste sentido, o estímulo para a realização de atividade física regular melhora a Qualidade de vida e promove a saúde.

Por outro lado, a educação normativa ainda é percebida no discurso e ressalta um processo educativo simplificado, voltado ao atendimento de requerimentos, imposição de novas regras e imediatismo.

"Muitas coisas que mudam, chega a hora que você precisa fazer uma reunião e muda." (Polônia)

Com os funcionários, tem reunião todos os dias e Quando vêm temas assim mais específicos, você não pode ficar omissa. Tanto a mudanças como a melhorias, da parte teórica. (Grécia)

Nós atuamos praticamente assistencial, mas eu faço a parte administrativa, assistencial e tudo ali. Então na dificuldade que um funcionário tem, nós vamos lá, fazemos juntos. (Itália)

Ressaltamos Que esta prática voltada ao imediatismo, por ser pontual e não-reflexiva, não tem os mesmos benefícios Que aQueles despertados a partir de uma prática educativa construída coletivamente, voltada à realidade de cada serviço, de cada trabalhador. Neste sentido, entendemos Que "a ação da Enfermagem para atendimento das atuais demandas da sociedade requer uma prática alternativa aos modelos convencionalmente desenvolvidos, coerentes com o exercício crítico-reflexivo de reconstrução do seu próprio processo de trabalho"(13).

A equipe eu sinto que ainda tem muito que melhorar nessa parte. Eu sinto que tem um modelo muito antigo, hospital mais fechado e aquela textura muito difícil. Acho que é um processo. Ainda to caminhando nesse sentido, acho que alguma coisa eu já devo ter conseguido, mas acredito Que é um processo. (França)

Nesse processo, o trabalhador deve superar visões e concepções lineares, parciais e alienantes. Assim, considerando a realidade contextualizada, poderão compreender a saúde e a educação em suas múltiplas dimensões, assumindo uma postura Que responderá às necessidades de saúde da população.

Outra categoria denominada Educação como formação básica e contínua foi identificada no conjunto de falas dos sujeitos, ao se perceber uma tendência a compreender a educação em saúde voltada ao compromisso com a formação profissional, havendo a necessidade da constante atualização e capacitação. Ainda, é necessária para Que os Enfermeiros possam corresponder ao papel de chefe de equipe.

Agora Quanto a minha experiência de docente eu procuro abrir muito os horizontes, porque a gente nunca sabe onde funcionário, esse futuro funcionário vai trabalhar. Uma aluna me disse: 'até parece Que tu me educas pra se professora, afinal eu vou fazer ou eu vou ensinar?' E eu disse que ela teria Que fazer ambos. (Chile)

Eu tenho prazer em pesquisar, é uma coisa que me estimula. Então àQuelas horas de folga que eu tenho pra me cuidar, eu to sempre no computador pesquisando alguma coisa que ficou pra trás, e aquilo é um prazer muito grande assim, eu não me canso. (Jamaica)

Há uma contínua evolução no processo de aprendizagem na área da saúde. É importante Que o profissional esteja atento às mudanças, buscando sempre e, principalmente, enQuanto docentes, uma educação transformadora, atualizada e crítica, conforme expressado por alguns sujeitos.

Eu acho que isso tudo é um processo. Tem Que melhorar. Tem Que sempre evoluir. Tem Que acompanhar, e pra isso, a gente não pode largar o estudo, largar livros, largar convivência. Acho Que é uma busca Que não termina nunca. (Egito)

No entanto, o modelo de ensino na Enfermagem, ainda vigente em instituições, é constituído de características próprias da escola tradicional, cujo perfil do profissional em formação é enfatizado no "desenvolvimento de habilidades técnicas, execução mecânica e acrítica de procedimentos manuais, no conhecimento clínico para o cumprimento da prescrição médica e no desenvolvimento da competência administrativa voltada para o gerenciamento do serviço e não do cuidado, em prol dos interesses da instituição e dos profissionais Que nela atuam e não das necessidades da população"(19).

Outros sujeitos da pesquisa consideram o processo educativo em saúde, apenas com simples repasse de informações, rotinas, conforme ilustrado por Canadá.

A gente lida muito com acadêmico aqui, pra mim isso é muito bom porque eu gosto. (...) A gente educa muito o pessoal da medicina, em relação ao material Que vai para o expurgo, em relação às rotinas, muitas vezes até em relação às prescrições. (Canadá) 
Pode-se perceber um posicionamento do professor / Enfermeiro como de aprendizagem unilateral: o aprendizado é repassado somente ao aluno e este "leva" este conhecimento da escola. Ainda, indica o educador como único responsável em instigar e estimular o aprendizado. $\mathrm{O}$ interesse pela aprendizagem deve partir de todas as partes no processo educativo, para Que ocorra, efetivamente, transformação do conjunto.

Com os alunos, Quando eu faço algumas abordagens específicas, percebo Que eles observam, prestam atenção, fundamentam e fazem troca. É o retorno do meu aluno, na verdade. Do aprendizado Que ele ta levando da escola, a gente também tem que dar o estímulo e ta na frente. Eu digo que a equipe é o espelho do Enfermeiro. E o professor não é diferente, a escola não é diferente. (Austrália)

Eu tenho bastante coisa a aprender, como a Questão da problematização, falta repetir a problematização, assim como a teoria das necessidades básicas são base pra mim, ela pode ser trabalhada até com o paciente, com acompanhante. (...) Eu mudei bastante, acho que é bem interessante a forma de ta trabalhando com isso, mas eu tenho muito a aprender ainda. (Nova Zelândia)

Alguns sujeitos manifestaram um entendimento de educação em saúde, enquanto docente, como processo que ocorre formalmente ou informalmente, com perspectiva de troca, ampliando o horizonte para promoção de saúde, conforme a fala de Mar da Tasmânia.

A Questão educativa tem uma forma mais formal, mais de escola, mas tem a forma informal, tu Que tu educa o teu filho o dia inteiro, tu ajudas a trocar informações com sua família, com seus amigos. Dentro do hospital, a gente é educadora em todos os momentos. A gente trabalha com acadêmicos de Enfermagem, então a gente está sempre passando informações pra eles. E vive trocando, não apenas dando informações. (Mar da Tasmânia)

O entendimento de educação em saúde com valorização do conhecimento científico e popular constituiu outra categoria denominada como Educação na perspectiva de aliança de saberes.

É indispensável relevar o "conteúdo empírico do conhecimento do educando, oriundo de sua vivência, de sua experiência constituída nas relações com a natureza e com os semelhantes ou seja, sua apreensão das situações de vida coletivamente acumulada"(20) uma vez Que, a partir desse conhecimento da realidade ele passa a desenvolver uma aprendizagem significativa.

Há a necessidade de manter respeito pelo saber cultural. A gente tem o saber científico, então vamos ter que fazer um inter-relacionamento harmonioso entre essas duas áreas. (MoçambiQue)

Na perspectiva de aliança de saberes, a educação em saúde aliada à promoção da saúde pode ser vista como "uma estratégia mediadora entre pessoas e ambiente, visando aumentar a participação dos sujeitos e da coletividade na modificação dos determinantes do processo saúde/doença, como emprego, renda, educação, cultura, lazer e hábitos de vida"(18).

Em contraponto, alguns sujeitos do estudo mantêm uma concepção de cultura enQuanto nível escolar entendendo a cultura do outro, de forma pejorativa. Neste sentido, percebemos que a educação ainda é entendida, por alguns dos sujeitos, como forma de convencimento e prescritiva.

A gente tem um grande inimigo: a cultura popular. Ouve aqui e sai ali. É tão difícil uma pessoa com um nível cultural um pouco melhor e lá a pessoa tem aquela cultura toda diferente, uma cultura difícil. Se tu não convences uma pessoa em casa, vai convencer um bairro inteiro? Tem gente Que precisa muita conversa pra tentar convencer, mas eu acho Que é gratificante sim. (Congo)

O entendimento de cultura enQuanto "limitação" deve ser entendida aQui como um ponto de partida para a prática educativa e não implica em fixar-se. Vale ressaltar Que é importante conhecer, identificar e respeitar a cultura dos indivíduos para Que seja possível concretizar uma educação não-neutra e libertadora.

A categoria Contribuição do ESPENSUL na aquisição da competência manifestou a relevância do Curso em sua totalidade e destacou algumas contribuições.

O ESPENSUL contribuiu de forma a abrir portas, trazer discussão, com um realce da importância da troca de saberes a partir da prática anteriormente vivenciada, para uma relação harmoniosa entre a prática e a teoria fortalecida no Curso. Neste sentido, a teoria "implica numa inserção na realidade, num contato analítico com o existente, para comprová-lo, para vivê-lo e vivê-lo plenamente, praticamente", visto Que a teoria não é auto-suficiente. Necessita da realidade e prática, para a transformação de algo Que se compreende (20). "Acho Que tudo contribuiu bastante, porque tivemos embasamento teórico, trocamos idéias com vários profissionais, com pessoas mais experientes." (Marrocos)

Alguns sujeitos indicam Que a ESPENSUL despertou reflexão, como exemplificado:

"A grande porta foi a ESPENSUL. Voltar a estudar, o interesse pela leitura, a ver a importância disso... Mostrou-me que a gente não pode estar longe de uma instituição de ensino." (Egito)

Ela me fez pensar muito a respeito do meu trabalho como profissional. Como eu utilizei, e muito, a humanização, se eu realmente era humana, mas não humana só com o meu cliente, mas todos aqueles com Quem eu me relacionava. (Somália)

Entendemos Que sem reflexão não há ação e Que, Quando há ação sem reflexão, esta, por si só, não é transformadora, visto Que mantém práticas arraigadas no comodismo, acrítica, sem ter a autenticidade dos indivíduos pensantes Que nela se encontram. Esta é a importância da Enfermagem: voltar-se a práticas educativas fundamentadas na realidade, enlaçada à pedagogia libertadora, para transformação dos sujeitos enQuanto seres cônscios e críticos, Que atuam no seu processo de saúde, transformando esta mesma realidade. 


\section{CONSIDERAÇÕES}

A competência atuar como educador em saúde junto à equipe, cliente e familiares, no desempenho de suas funções estabelecida no ESPENSUL, envolve não somente a intencionalidade do Curso e de seus professores, mas sim, um comprometimento de todos com o processo de mudança. Toda mudança implica em rupturas, principalmente com a saída da acomodação com a situação em Que vivemos, a Qual dominamos, conhecemos, e portanto, não tememos. Por isso ela é tão difícil. A abertura para a mudança, como atitude deliberada e consciente, demonstra um movimento de rompimento com estes paradigmas, Que apesar de lento, se expressa na ruptura da regularidade.

Este Curso, ao utilizar o referencial da educação em saúde como um processo dialógico, inclusivo e problematizador, Que visa à construção da consciência crítica conjunta sobre o ser e o estar dos indivíduos no mundo, estimulou nos Enfermeiros algumas mudanças no processo educacional da sua prática cotidiana. Mudanças para Que a educação em saúde não seja vista apenas como repasse de informações, como uma prática rotineira sem reflexão, acomodativa, sem criticidade, sem interferência do indivíduo que, pensante e inteligente, pode transformar-se e transformar seu contexto. A mudança pedagógica que nos referimos, encontra-se aQuém de uma prática acomodativa ou reformista, mas sim, uma prática educacional transformadora, criativa, Que envolve todos os sujeitos para a superação de limitações, trazendo responsabilidade, autonomia e Que, entre outros diversos fatores, oportuniza ampliar a visão de mundo.

No contexto da educação em saúde transformadora, os envolvidos despertam para uma prática inclinada à tão fundamental promoção de saúde. Esta tem papel relevante na construção de uma sociedade civil organizada, participativa e, ainda, estabelece relações horizontais, com posteriores ações de inclusão social em saúde. No entanto, ainda percebese na prática de alguns sujeitos deste estudo, uma dificuldade, nos serviços de saúde, em concretizar o Que suas propostas teóricas prevêem: prática educacional transformadora, levando em conta o reconhecimento das necessidades individuais e locais, envolvimento da instituição/setor governamental na contribuição para a inclusão social Que auxilie a diminuir as iniQüidades, educação não-acodomodativa ou apenas reformista com a equipe de Enfermagem e o estímulo e fortalecimento da participação popular.

Assim sendo, não podemos esperar profissionais comprometidos com o desenvolvimento de uma sociedade ou nação, se não lhes foi proporcionado, pela instituição formadora, subsídios para o desenvolvimento de uma visão crítica, do contexto histórico-social em Que está inserido, conforme o ESPENSUL visou proporcionar. Neste aspecto, deve-se esperar tanto da Universidade Quanto dos cursos de especialização, o compromisso em não reduzir o aluno ao tecnicismo, a um "autômato manipulável".

O ESPENSUL proporcionou a seus Enfermeiros especialistas uma contribuição no tocante a educação em saúde, como expressado, unânime, pelos sujeitos deste estudo. Certamente contribuiu na aQuisição desta competência, Que parece encontrarse em contínuo desenvolvimento não só pelos profissionais, como pela sociedade. Neste sentido, ainda é percebida a necessidade de aperfeiçoamento dos métodos de ensino adotados pelos Enfermeiros, para voltar-se para uma prática transformadora.

A formação contínua contribui sobremaneira, visto ser um processo Que remete primeiramente a uma revisitação interna de valores, com posterior reflexo no nível profissional. Leva em consideração o saber adQuirido pelo profissional nas experiências de trabalho, cuja valorização permite apontar com maior propriedade a realidade desse serviço, a expressão de suas necessidades e problemas, estimulando no processo de formação/ educação contínua, a troca mútua de experiências, a criação de novo saber e nova prática, a partir da crítica e instrumentalização gerada pela vivência deste processo.

O processo educativo e a formação do cidadão, profissional de saúde é um processo que envolve o compromisso com a vida, compreendendo formação não como conformar ou modelar, mas sim, como denomina Zabalza(21), uma "formação formativa", Que Qualifica o profissional e o desenvolve como sujeito.

\section{REFERÊNCIAS}

I. Dias LPM, Prado ML, Silva DMGV, Cartana MHF. Avaliando a implementação de um curso de especialização: um foco em novidades. Texto Contexto Enferm 1999; (8):133-41.

2. Jordan LH, Kuhlhoff MHR, Bohmgahren MF. Processo de aprendizagem do grupo de enfermeiras do Hospital Municipal São José/Joinville no curso de especialização em projetos assistenciais - ESPENSUL. Texto Context Enferm 1999; (8): 99- 103.

3. Machado MFAS, Monteiro EMLM, Queiroz DT, Vieira NFC, Barroso MGT. Integralidade, formação de saúde, educação em saúde e as propostas do SUS - uma revisão conceitual. Ciência Saúde Coletiva 2007; 12(2): 335-42.

4. Lüdke M, André M. Pesquisa em educação: abordagens Qualitativas. São Paulo: EPU; 1988.

5. Polit DF, Hungler BP. Fundamentos de Pesquisa em Enfermagem. $3^{\mathrm{a}}$ ed. Porto Alegre: Artes Médicas; 1995.

6. 6 Mohr LB. Impact analysis for program evaluation. London: Sage Publications; 1995.

7. Savedra MMG. Avaliação do impacto dos programas orientados da Fundação Carlos Chagas Filho de amparo à pesQuisa do estado do Rio de Janeiro. In: VII Congresso Internacional del CLAD sobre la reforma del Estado y la Administración Publica. 8-1I oct, 2002 Lisboa (PT). Lisboa: CLAD; 2002.

8. Bagnato MH. Educação contínua na área da saúde: uma aproximação crítica. In: Educação, saúde e trabalho: antigos problemas, novos contextos, outros olhares. Campinas: Alínea; 1999.

9. Freire P. Pedagogia do oprimido. Rio de Janeiro: Paz e Terra; 1987.

10. Reibnitz KS, Prado ML. Inovação e educação em enfermagem. Florianópolis: Cidade Futura; 2006.

11. Backes VMS. Estilos de pensamento e práxis na enfermagem: a contribuição do estágio pré-profissional. ljuí: UNIJUÍ; 2000.

12. Freire P. Educação e mudança. $23^{\mathrm{a}}$ ed. Rio de Janeiro: Paz e Terra; 1999

13. Delizoicov D, Angotti JA, Pernambuco MM. Ensino de ciências: fundamentos e métodos. São Paulo: Cortez; 2002. 
14. World Health Organization. Health promotion evaluation: recommendations to policymakers. Copenhagen: European Working Group on Health Promotion Evaluation; 1998.

15. Dias MR, Duque AF, Silva MG, Durá E. Promoção da Saúde: o renascimento de uma ideologia? Análise Psicológica 2004, 3 (22): 463-73.

16. Lino MM, Backes, VMS, Schmidt SMS, Ferraz F, Prado ML, Martins ST. The reality of nursing continuing education in the public health services: a descritive study. Online Braz I Nurs 2007;(6).

17. Carvalho SR. As contradições da promoção à saúde em relação à produção de sujeitos e a mudança social. Ciência Saúde Coletiva 2004; 9(3): 669-78.
18. Aerts D, Alves GG, La Salvia M W, Abegg C. Promoção de saúde: a convergência entre as propostas da vigilância da saúde e da escola cidadã. Cad Saúde Pública 2004; 20(4): 1020-8.

19. Loureiro MM, Vaz MRC. A busca de novos modelos de ensino: condição essencial para a transformação do modelo assistencial de Enfermagem. Texto Contexto Enferm 2000; 9(2): 226-37.

20. Freire, P. Educação como prática da liberdade. Rio de Janeiro: Paz e Terra; 1983.

21. Zabalza M. O ensino Universitário seu cenário e seus protagonistas. Porto Alegre: Artmed; 2004. 